\title{
Augenblick und Ewigkeit
}

S. Weiss

Unter diesem Titel fasste der Architekt Jean Nouvel das gesamte Städtchen Murten während der Expo.02 zusammen, wobei die Ringmauern und die ganze Stadt in die Planung einbezogen wurden. Im Vergleich zu den drei andern Arteplages, die am Seeufer abgetrennt von den Städten Biel, Yverdon und Neuchâtel geschaffen wurden, wirkte Murten deshalb als harmonisches Ganzes.

Die malenden Ärzte der Schweiz hatten die einzigartige Gelegenheit, während der Expo.02 im Zentrum dieses wunderbaren Ortes, nämlich im Rathaus, ihre jährliche Ausstellung zu gestalten. Das Thema der Arteplage Murten war für viele gestaltende Kolleginnen und Kollegen ein Ansporn, ihre diesjährigen Schöpfungen unter den Titel der Arteplage zu stellen. So wurden Plastiken, Bilder, sogar ein ganzer mit Bildern ergänzter Gedichtzyklus geschaffen. Besonders originell wurde auch eine Videoinstallation präsentiert, die wie die bekannten Installationen des Videokünstlers Nam Yun Paik während der ganzen Ausstellung Bilder des Augenblicks und der Ewigkeit über den Bildschirm flimmern liess.

Bereits die Vernissage der Ausstellung wurde ein schönes Erlebnis mit musikalischen Darbietungen des komponierenden Kollegen U. Ammann, Interlaken, und den immer wieder feinen Kompositionen von J. L. Darbellay, Bern, die von den Künstlern selbst uraufgeführt wurden. Wieder wurden Gedichte von Kollegen vertont und mit heiteren und oft launischen Ausführungen des Komponisten ergänzt. Wie in den vergangenen Jahren stimmte die ruhevolle, wunderbare französische Kirche das zahlreich zum Konzert erschienene Publikum erwartungsvoll auf die anschliessende Eröffnung unserer Ausstellung ein. Wir waren sehr froh darüber, dass wir die Kirche auch dieses Jahr wieder für unser Konzert benutzen durften, obwohl sie während der ganzen Expo.02 im Rahmen der Darbietung der Schweizerischen Kirchen zum Ort der Ruhe und Stille umfunktioniert worden war.

Der Publikumsandrang war bereits während traf diejenige der Vorjahre um ein Mehrfaches.

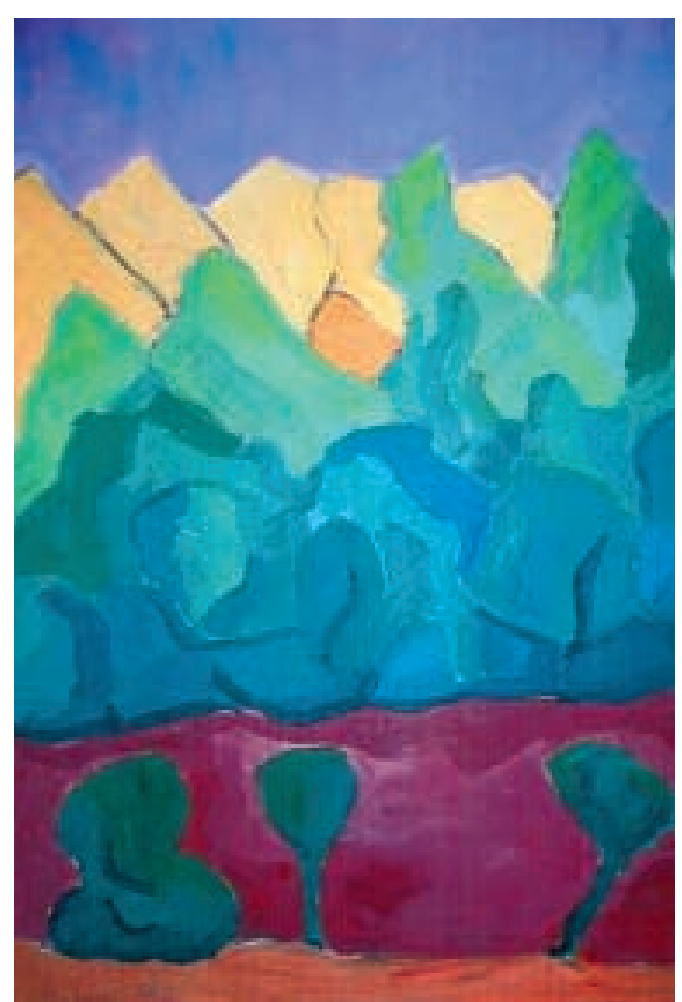

Gebirgslandschaft im Wallis. Öl auf Leinwand. Philipp Lyrer, Basel.

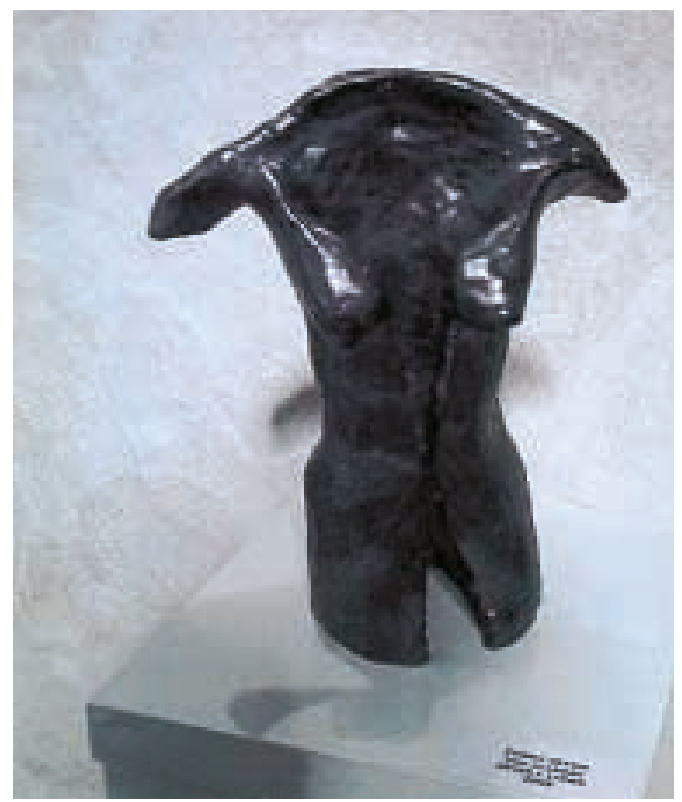

Torso Frau. Plastik. Peter Luder, Bern. 
Einer der Einträge in unserem Gästebuch war für eine malende Kollegin besonders interessant: «Félicitations à F.B. Vous pouvez prendre contact avec nous. Galerie le Soleil-Bleu, 8, rue du Général Leclerc, F-78000 Versailles.» So wurde ihr vielleicht der Weg in die grossen Galerien von Frankreich eröffnet. Unsere Vereinigung freut sich immer über Neuanmeldungen. Sicher schlummern da und dort unentdeckte Talente, die plötzlich wach werden. Kunst in der Gemeinschaft inspiriert. Alles Weitere erfahren Sie beim Präsidenten der Vereinigung.
Hommage à Jean Nouvel. Drucktechnik. Lis Weiss, Bern.

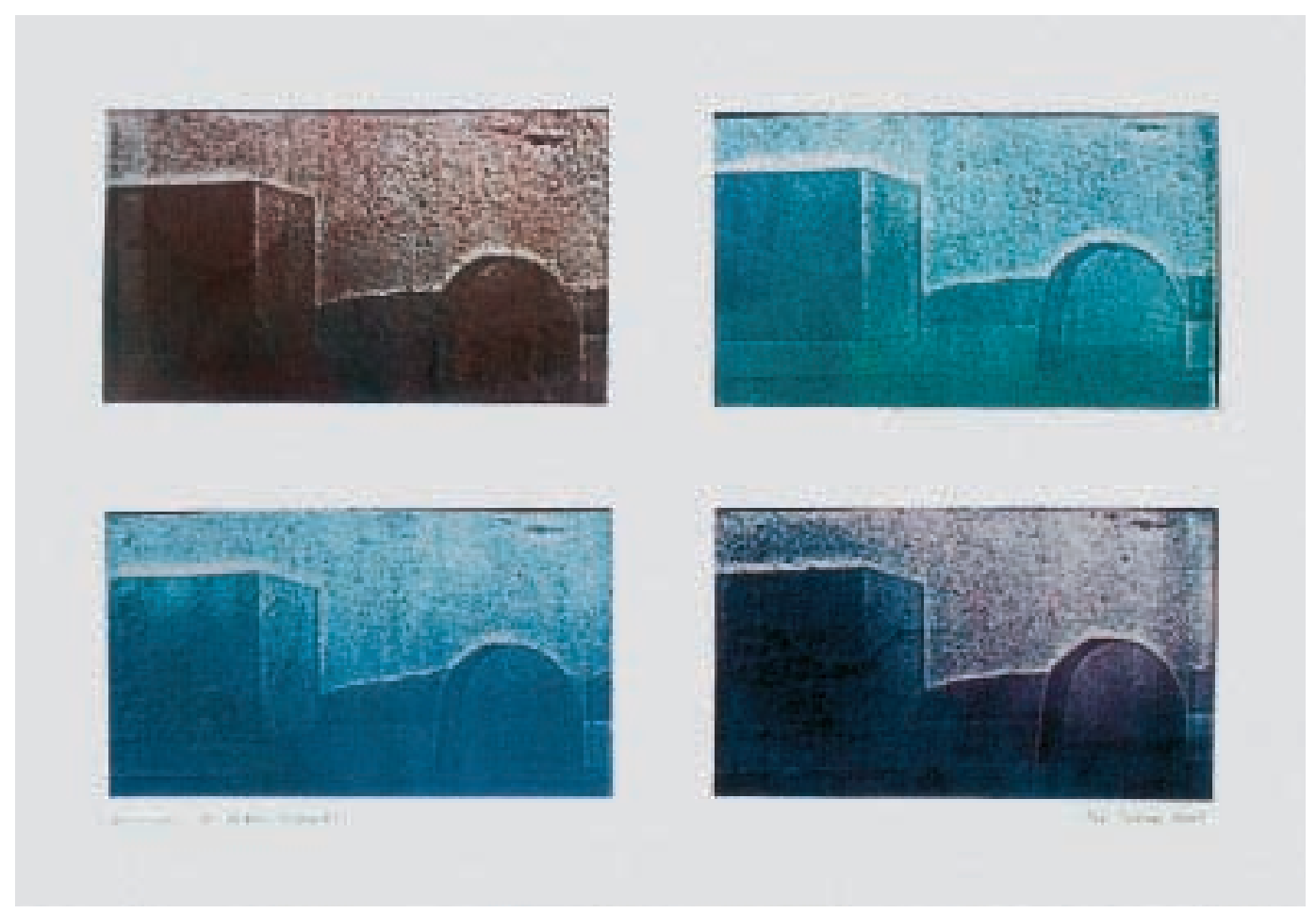

Nacht in China Town. Mischtechnik. Frank Gafner, Liestal.

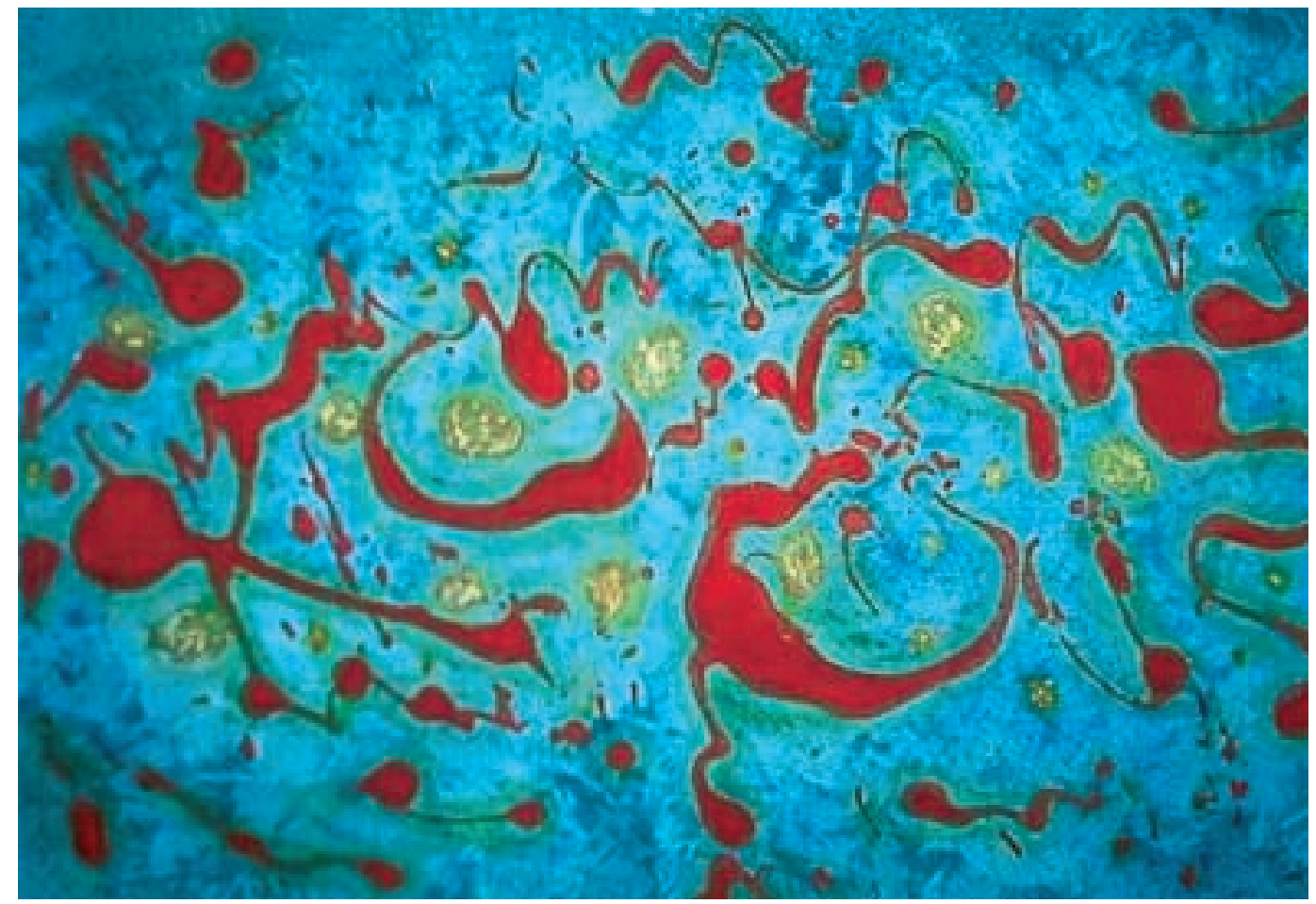

